\title{
Detection of monsoonal phytoplankton blooms in Luzon Strait with MODIS data
}

\author{
Eileen L. Peñaflor ${ }^{\mathrm{a}, *}$, Cesar L. Villanoy ${ }^{\mathrm{a}}$, Cho-Teng Liu ${ }^{\mathrm{b}}$, Laura T. David ${ }^{\mathrm{a}}$ \\ ${ }^{a}$ Marine Science Institute, University of the Philippines, Diliman, Quezon City, 1101 Philippines \\ ${ }^{\mathrm{b}}$ Institute of Oceanography, National Taiwan University, Taipei, Taiwan
}

Received 9 August 2006; received in revised form 23 January 2007; accepted 27 January 2007

\begin{abstract}
The Luzon Strait experiences a seasonal surge of phytoplankton based on ocean color data. To examine the timing and position of the bloom, daily MODIS chlorophyll data (2002-2005) were acquired and analyzed. Supporting data such as MODIS SST and nLw bands, QuikSCAT wind data, river discharge, and bathymetry were also used and processed in order to investigate the possible driving forces behind the bloom occurrence. Results show that chlorophyll concentration in the Luzon Strait dramatically increases during NE monsoon reaching to approximately $2.0 \mathrm{mg} / \mathrm{m}^{3}$. Highest chlorophyll concentration is observed near the western slope of the Luzon Strait. The monsoonal bloom in the Luzon Strait is likely due to upwelling and can be possibly associated with the interaction of the northward flowing Luzon coastal current with the westward intrusion of Kuroshio during NE monsoon. The positive wind stress curl also contributes to this occurrence. The influence of Cagayan River is only limited within few kilometers from the river mouth.
\end{abstract}

(C) 2007 Elsevier Inc. All rights reserved.

Keywords: Luzon Strait; Phytoplankton bloom; Sea surface temperature; Wind stress curl

\section{Introduction}

The Luzon Strait is the main channel through which effective water exchange between the Western Pacific Ocean (WPO) and the South China Sea (SCS) occurs. The strait has a width of about $350 \mathrm{~km}$ and has a sill depth of $1900 \mathrm{~m}$ (Chen et al., 2003; Farris \& Wimbush, 1996; Liu et al., 2002). The other channels surrounding the SCS are either too narrow or too shallow to allow effective interaction with its surrounding waters (Chen et al., 2004; Metzger \& Hurlburt, 2001a).

Along the northern east coast of the Philippines runs the northward flowing Kuroshio current. This current is formed from the bifurcation of the North Equatorial Current (Fig. 1a) near the east coast of the Philippines at approximately $13^{\circ} \mathrm{N}$ (Toole et al., 1990). Studies have shown that Kuroshio penetrates the northern SCS through the Balintang Channel and the passage south of Babuyan Island in Luzon Strait, (Centurioni

\footnotetext{
* Corresponding author. Tel.: +63 2922 3957; fax: +632924 7678
}

E-mail address: elpenaflor@yahoo.com (E.L. Peñaflor). et al., 2004; Metzger \& Hurlburt, 2001b). This penetration brings in Kuroshio's top $300 \mathrm{~m}$ water westward until the continental slope of northern SCS (Shaw \& Chao, 1994). The intrusion, henceforth referred to as the Luzon Strait loop current, has its most severe penetration during the months of October-January (Centurioni et al., 2004), concurrent with the northeast (NE) monsoon. The westward movement of the Kuroshio is believed to be related to Ekman advection due to the direction of the wind during NE monsoon. A reasonable relationship between loop-current stage and wind stress history was derived by Farris and Wimbush (1996).

The deep water from the WPO also enters the SCS through this strait, which will become the deep SCS water (Liu et al., 2002; Nitani, 1972). This is evident in the water characteristics of SCS below the sill depth, which has been found to resemble those in the WPO water at sill depth (Chen \& Huang, 1996; Nitani, 1972). The deep SCS water, on the other hand, is believed to upwell and combine with the surface water forming the mid-depth SCS water (Gong et al., 1992; Liu et al., 2002). This intermediate layer of water constitutes the water mass that 

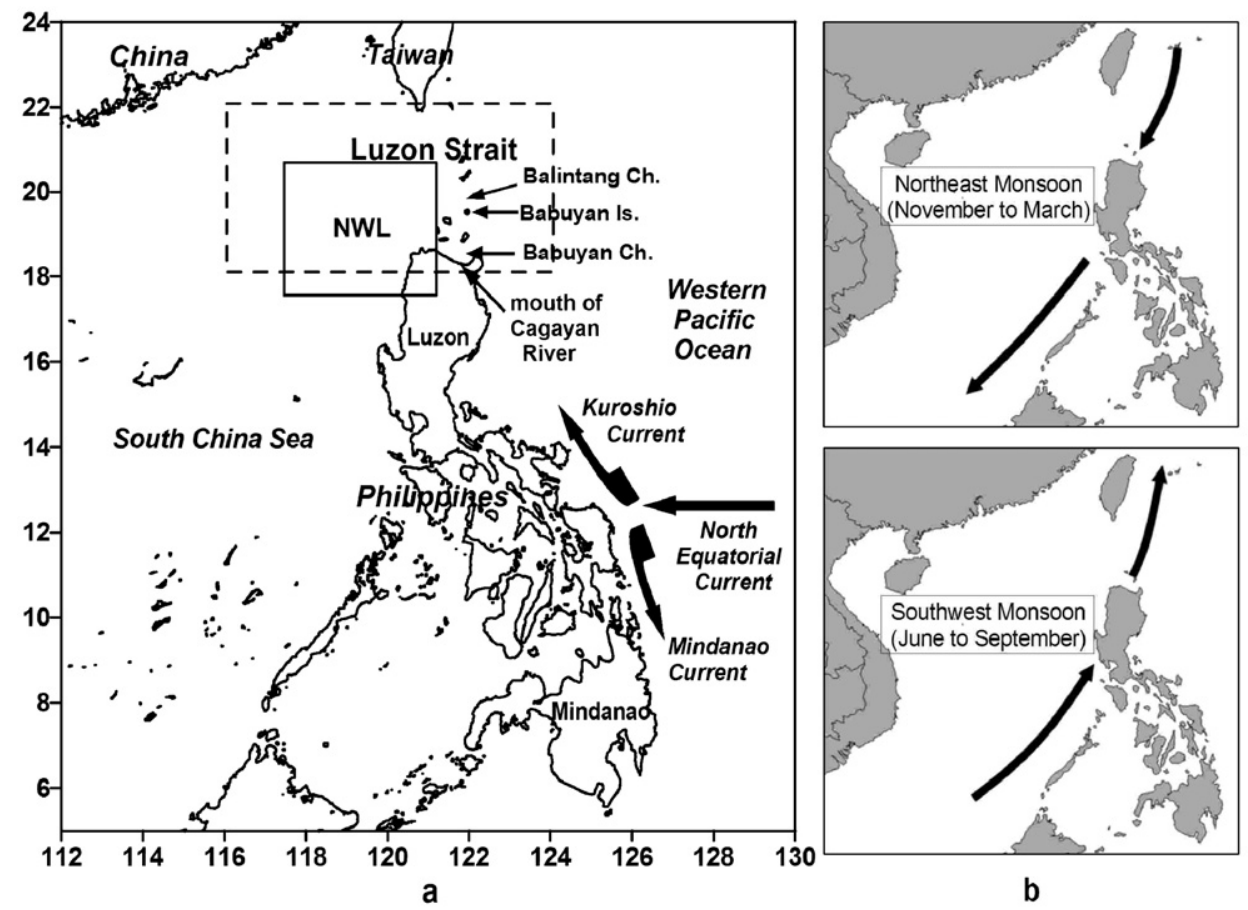

Fig. 1. (a) Map of the Philippines and its surrounding areas. The box inside (in broken lines) covers the area where monthly average chl- $a$ and SST values were extracted. NWL box represents the northwest of Luzon area (b) Monsoon seasons. Arrows depict the wind direction.

flows out of the SCS through the northern end of Luzon Strait, joining the northward flowing Kuroshio (Chen \& Huang, 1996; Chen et al., 2001; Liu et al., 2002) at the southeastern coast of Taiwan. This upwelling results in an uplift in nutricline and thermocline in the SCS in contrast to that of the WPO side (Gong et al., 1992; Liu et al., 2002).

Areas of localized upwelling have been identified in the various parts of the SCS (Chao et al., 1996; Liu et al., 2002; Shaw et al.,1996; Tang et al. 1999; Udarbe-Walker \& Villanoy, 2001). A study by Liu et al. (2002) shows that the deep chlorophyll maximum depth to the west of Luzon changed from about $75 \mathrm{~m}$ in September 1998 to about $40 \mathrm{~m}$ in January 1999, suggesting an occurrence of seasonal upwelling in the area. Furthermore, analysis of historical hydrographic data conducted by Udarbe-Walker and Villanoy (2001) showed a core of cold water centering at $18^{\circ} \mathrm{N}, 119^{\circ} \mathrm{E}$ in January-March. Monthly temperature profile at the center of the core shows uplifting of isotherms starting in October with maximum upward displacement in January, signaling the presence of upwelling. This upwelling is most likely connected to the winter phytoplankton bloom southwest of Luzon Strait (within the NWL box in Fig. 1a) as observed by Tang et al. (1999) using Coastal Zone Color Scanner (CZCS) data. Upwelling to the west of Luzon during NE monsoon has been attributed to subsurface convergence of the northward coastal current west of Luzon (Chao et al., 1996; Shaw et al., 1996, hereafter referred to as Luzon Coastal Current or LCC) and to positive wind stress curl $(\mathrm{Qu}$, 2000). In addition, studies have shown that during NE monsoon season several cyclonic eddies, which can also induce upwelling, are formed on this area (Hu et al., 2000; Wang et al., 2003).
The alternating monsoons have an enormous influence on the productivity in SCS and in Luzon Strait, in particular, but some other factors may also have a contribution. Pinazo et al. (2001) showed that the nutrients carried in the freshwater runoff, together with the influence of local winds, have significant effect in increasing the phytoplankton biomass in the Gulf of Lions in the Mediterranean. The effect of tides, coupled with wind regime, has also shown to influence the formation of phytoplankton bloom in some areas. In the Strait of Gibraltar, the injection of the nutrient-laden North Atlantic Water to the strait is highly favored during neap tides when inflow is maximum and enhanced during westerlies when surface Atlantic waters are pushed to enter the strait increasing the local productivity of the area (Gomez et al., 2004). In addition, biological productivity is also enhanced in areas around oceanic islands. This phenomenon, also known as "island mass effect", is due to various mechanisms. One of which is the formation of wakes and eddies on the leeward of the island, in which formation depends on the Reynolds number (Tomczak, 1998). Others include seepage from land drainage and hydrothermal fluxes (Signorini et al., 1999) and internal wave mixing that induce upward transport of cold, nutrient-rich water (Sangra et al., 2001).

In Luzon Strait, where seasonal phytoplankton bloom has been documented, examining the patterns of bloom formation in the area is significant for fisheries management. Understanding the various factors involved in the occurrence of phytoplankton bloom is also necessary. This study, therefore, (1) presents the patterns of wane and wax of phytoplankton in the strait and (2) examines the various contributing factors to the productivity of this area. 


\section{Data and methods}

\subsection{MODIS chl- $a$ and SST}

Moderate Resolution Imaging Spectroradiometer (MODIS) surface chlorophyll- $a$ (chl- $a$ ) and sea surface temperature (SST) were the primary data used in this study. Processed MODIS level 2 data with an average of 24 daily images for each month from July 2002-May 2005 were downloaded from the National Aeronautics and Space Administration-Goddard Space Flight Center (NASA-GSFC) at their website at http://oceancolor.gsfc. nasa.gov/. Each data file already contained the derived chl- $a$, $\mathrm{SST}$, and the six normalized water-leaving radiances (nLw, see http://oceancolor.gsfc.nasa.gov/PRODUCTS/nlw.html). The downloaded $1 \times 1 \mathrm{~km}$ resolution MODIS data cover $17-24^{\circ} \mathrm{N}$ and $110-124^{\circ} \mathrm{E}$. Each image was regridded so that all images would have a common grid system.

Extraction of the daily chl- $a$ and SST bands was then made. Image selection was done to remove images with no data and monthly average composites were computed by simply averaging daily chlorophyll values available for each grid. The study area was narrowed to $116-124^{\circ} \mathrm{E}$ and $18.3-22^{\circ} \mathrm{N}$ (see inside box in broken line Fig. 1a) to better emphasize the temporal variation in monthly average chl- $a$ concentration and SST in the strait. Pixel correlation between the two parameters using the monthly composites of 2004 was also performed and a correlation coefficient map was produced. The reason for choosing 2004 monthly images was based on the fact that 2004 was an El Niño year (although weak, see http:/www.cpc.noaa.gov/products/ analysis_monitoring/ensostuff/ensoyears.shtml) when Kuroshio intrusion is considered weaker (Ho et al., 2004) thus minimizing the influence of Kuroshio, if indeed the intrusion of the current has a huge effect on the biological productivity in the study area. Year 2002 was also an El Niño (weak) but was not used for the correlation due to incomplete dataset for the whole year.

Manual tracing of thermal fronts was also performed. This was done to show the influence of the major currents in the study area. Thermal fronts were identified by its abrupt jump in SST. The December 2003 SST composite image was utilized here because of its sharp contrast in SST, thus easier to trace. Furthermore, areas with the highest chl- $a$ concentration were also traced. Monthly images from November 2003 to March 2004, to represent the NE monsoon months, were used.

\subsection{QuikSCAT-derived wind stress curl}

The wind data used in this study were taken from the NASAJet Propulsion Laboratory (JPL). Daily QuikSCAT Level 3Derived Multialgorithm Surface Wind Stress data (2002-2004) were downloaded from the NASA-JPL ftp site at ftp://podaac.jpl. nasa.gov/pub/ocean_wind/quikscat/L3/. The level 3 data are provided on a global grid of 1440 pixels in longitude by 720 pixels in latitude $\left(0.25^{\circ}\right.$ by $\left.0.25^{\circ}\right)$. This wind product contains the ascending and descending wind stresses for both $u$ and $v$ components, which were calculated from two algorithms (Large \& Pond, 1981; Liu \& Tang, 1996), as described in the JPL QuikSCAT webpage.
Wind stress curl at each $0.25^{\circ} \times 0.25^{\circ}$ grid point that encompassed the study area was then calculated by first averaging the ascending and descending wind stress for both components and then applying the algorithm for calculating the curl (CERSAT - IFREMER, 2002). Frequency of positive wind stress curl greater than $0.05 \times 10^{-5} \mathrm{~N} \mathrm{~m}^{-3}$ for each month was then extracted to highlight probable upwelling sites. Monthly values of wind stress curl at the core of the identified upwelling site were taken and correlated with monthly chl- $a$ concentration. This correlation was applied for 2004 monthly composites.

\subsection{MODIS-derived suspended sediment}

Additional analysis on total suspended sediment (TSS) as proxy for determining river discharge influence was made. From the daily MODIS files that were downloaded, as described in Section 2.1, nLw 443 and 551 were extracted. This was followed by the derivation of the monthly composites of the two bands. TSS calculation was then made by utilizing the monthly images of the two bands and applying the Eq. (1) as described in Delu et al. (1999).

tss $=3.2602 *\left(R_{443} / R_{551}\right)^{-3.9322}$

R443 and R551 represent the nLw $443 \mathrm{~nm}$ and $551 \mathrm{~nm}$, respectively. The original equation utilized the $443 \mathrm{~nm}$ and $555 \mathrm{~nm}$ channels of SeaWIFS. Furthermore, the monthly TSS images of 2004 were later used to correlate with the mean monthly river discharge data of Cagayan River. All the calculations were done using Matlab.

\subsection{River discharge}

River discharge data were also collected to provide information on the peak flows and months and the possible influence of the nearby rivers to the phytoplankton distribution in the study area. River discharge information for Cagayan River was downloaded from SAGE River Discharge Database at http:// www.sage.wisc.edu/riverdata/.

\subsection{Bathymetry}

Bathymetric data was also utilized in this study as supporting data. Bathymetric grid of the study area was extracted from the General Bathymetric Charts of the Oceans (GEBCO, www. bodc.ac.uk) 2003 digital atlas. The global bathymetric grid has a one-minute resolution.

\section{Results}

\subsection{Seasonal variation in chl-a concentration and SST}

The 35 monthly images of chl- $a$ revealed a seasonality in the abundance of phytoplankton in Luzon Strait. Fig. 2a shows a relatively low chl- $a$ concentration during southwest (SW) monsoon as compared to the dramatic increase in chl- $a$ during NE monsoon months, indicating an increase in phytoplankton 

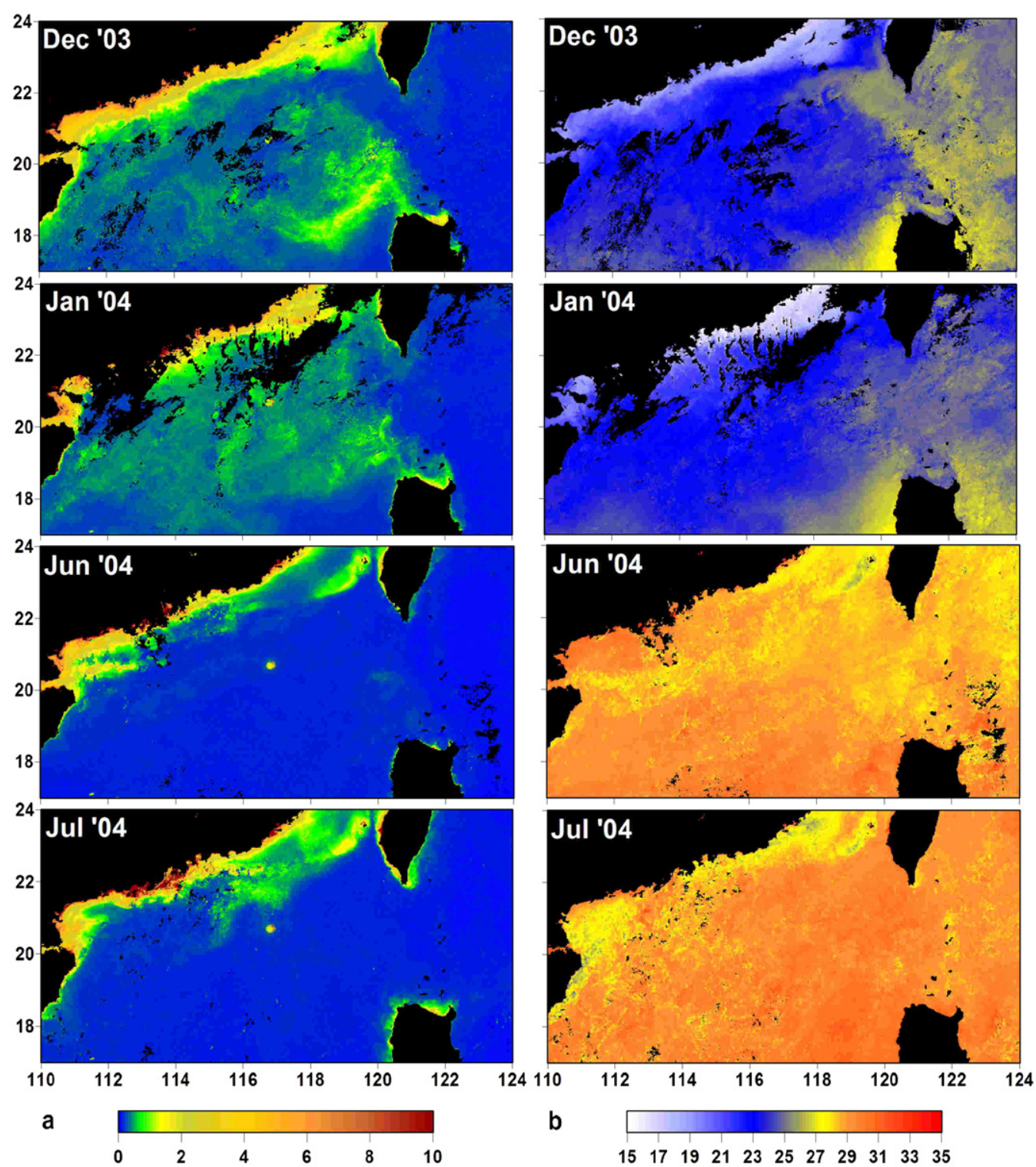

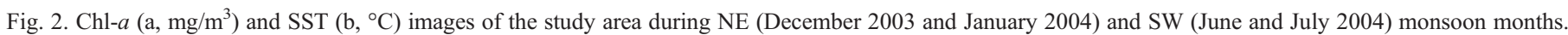
Masked areas (land and cloud) are presented here in black.

biomass in the area. In the NWL area where the highest concentration can be observed, chl- $a$ reaches to a maximum of approximately $2.0 \mathrm{mg} / \mathrm{m}^{3}$ in December (2003 and 2004). During SW months, however, concentration in the area reaches to only about $0.2 \mathrm{mg} / \mathrm{m}^{3}$ (except on the northern coast of Luzon). A constantly high surface chl- $a$ concentration can only be observed along the northern coast of Luzon. Dongsha Atoll near $17^{\circ} \mathrm{N}$ and $121^{\circ} \mathrm{E}$ appears as a small persistent spot of high chlorophyll. This is probably due to contamination by shallow bathymetry of the atoll.

Concurrent with the bloom is the occurrence of relatively cooler temperature in areas with high chl- $a$ concentration (see NWL area). At the same time, a distinctively high SST to the east of Luzon that stretches across the Luzon Strait and to the west of Luzon can also be observed, creating thermal fronts (see Fig. 2b Dec 03 image). This is in contrast to the non-bloom months when there is an almost uniform distribution of high SST.
A plot showing the temporal changes in the chl- $a$ and SST is presented in Fig. 3. High chl- $a$ concentration coupled with a low SST can be observed during November-March, although a very slight increase in chl- $a$ can already be observed in October. The peak in chl- $a$ concentration shifts between November to March in different years. Calculated monthly average for all years, on the other hand, revealed the highest chl- $a$ concentration in December $\left(0.306 \mathrm{mg} / \mathrm{m}^{3}\right)$. The SST, however, shows a consistently lowest temperature during the month of January averaging to $24.34{ }^{\circ} \mathrm{C}$.

A spatial field of temporal correlation between chl- $a$ and SST is shown in Fig. 4. A high negative correlation exists on the region $117-120^{\circ} \mathrm{E}$ and $18-21^{\circ} \mathrm{N}$ (in NWL). This area also experiences seasonal elevation in chl- $a$ concentration. Very low correlation can be observed in areas with relatively higher SST (to the west and to the east of Luzon extending across the strait) and on the northern coast of Luzon where a consistently high chl- $a$ concentration occurs. 


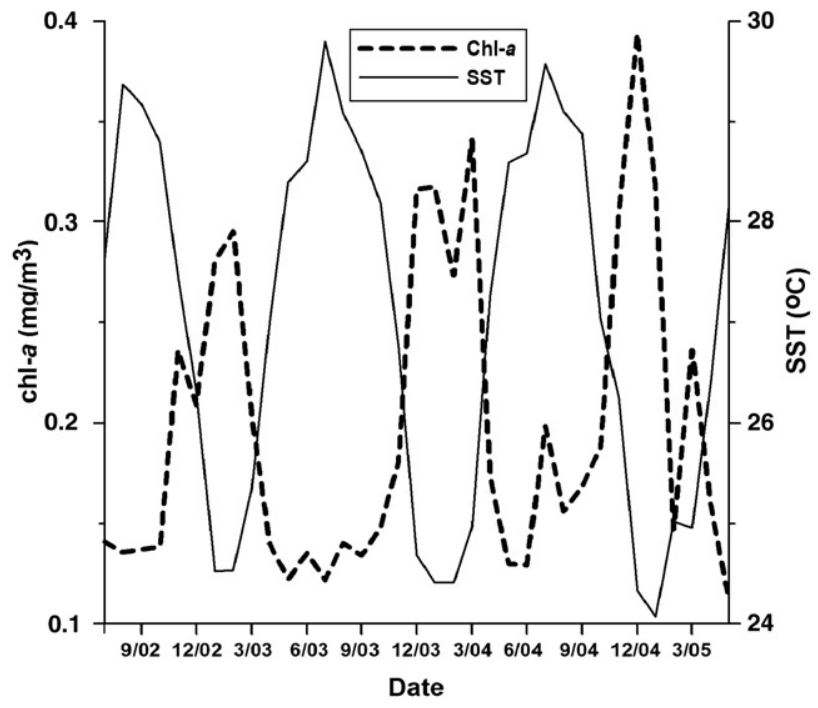

Fig. 3. Time series of monthly average surface chl- $a$ concentration and SST in the area defined in Fig. 1a.

\subsection{The influence of Kuroshio intrusion}

The pattern of distinct thermal fronts due to the westward intrusion of Kuroshio and the northward movement of LCC was also observed during NE monsoon. Overlaying these traced fronts on a chl- $a$ image (Fig. 5a) shows that a sudden increase in chl- $a$ concentration can be observed to the west side of the Kuroshio front and to the north of the LCC front. This could suggest that the currents in the northern SCS, specifically that of Kuroshio, highly influence the observed seasonal elevation of chl- $a$ concentration in the area. The presumed paths of Kuroshio are shown in Fig. 5b. The blue lines 1 and 2 are based on SST image while 3 is the path of the current as it loops at the northern part of the strait, after Farris and Wimbush (1996). During NE monsoon, part of the current can move towards the northern SCS (Fig. 5b(1)) and towards the western coast of Taiwan $(5 \mathrm{~b}(2))$ while part of it loops and moves towards the eastern coast of Taiwan.

Furthermore, areas with the highest chl- $a$ concentration during NE monsoon months were found to congregate on

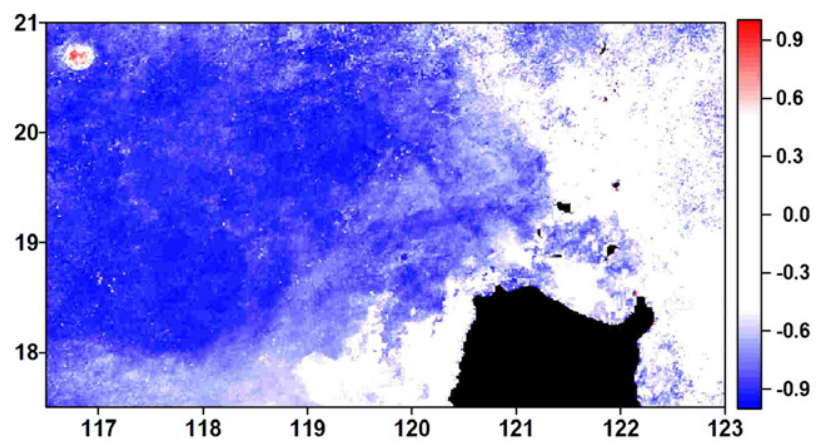

Fig. 4. Correlation coefficient ( $r$ ) between chl- $a$ and SST for 2004. Colored areas represent areas where $|r| \geq 0.5$. The patch with a high correlation on the top leftmost part of the image is Dongsha Atoll.
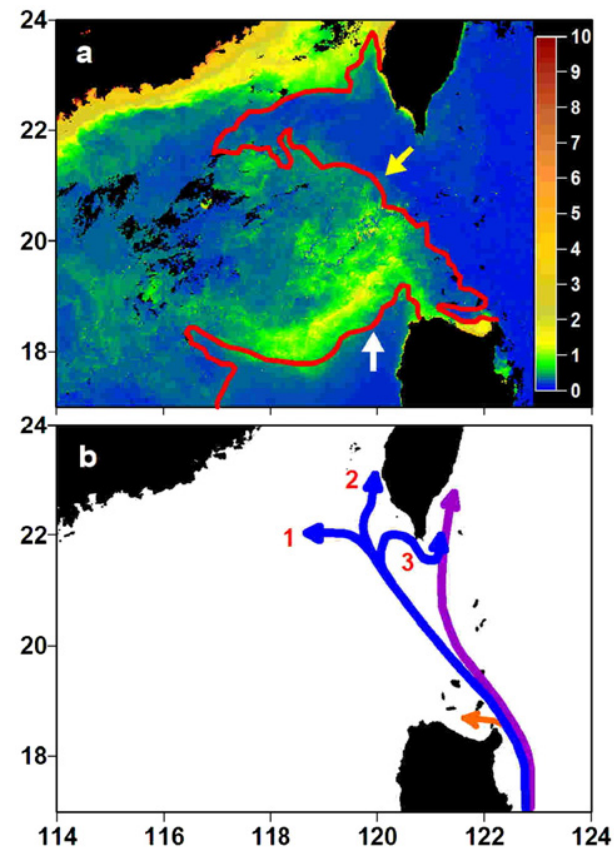

Fig. 5. (a) Traced fronts from December 2003 MODIS SST image due to the intrusion of Kuroshio (yellow arrow pointing) and the northward movement of LCC to the west of Luzon (white arrow pointing) overlayed on the December 2003 MODIS chl- $a$ image (in $\mathrm{mg} / \mathrm{m}^{3}$ ). (b) Lines represent the different paths of Kuroshio Current across the strait. Purple: direct path of the current. Blue: intrusion of Kuroshio in the northern SCS. Orange: branch of Kuroshio penetrating the Babuyan Channel. (For interpretation of the references to colour in this figure legend, the reader is referred to the web version of this article.)

the western slope of the Luzon Strait (Fig. 6). The cluster of highest chl- $a$ tends to intensify and move southward throughout the NE monsoon season as westward intrusion of Kuroshio strengthens.

\subsection{The influence of wind}

High frequency of positive wind stress curl can be observed to the west of Luzon, centering at approximately $119.54^{\circ} \mathrm{E}$ and $17.49^{\circ} \mathrm{N}$. Results show that this high frequency of positive curl occurs in October until March, coinciding with the timing

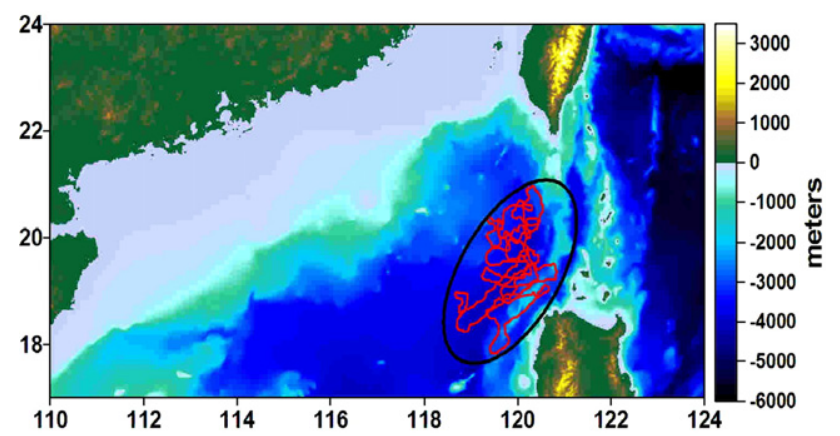

Fig. 6. Traced areas of highest chlorophyll concentration from November 2003March 2004 (NE monsoon months) overlayed on a bathymetric map. An ellipse encloses these areas of highest chlorophyll concentration. 

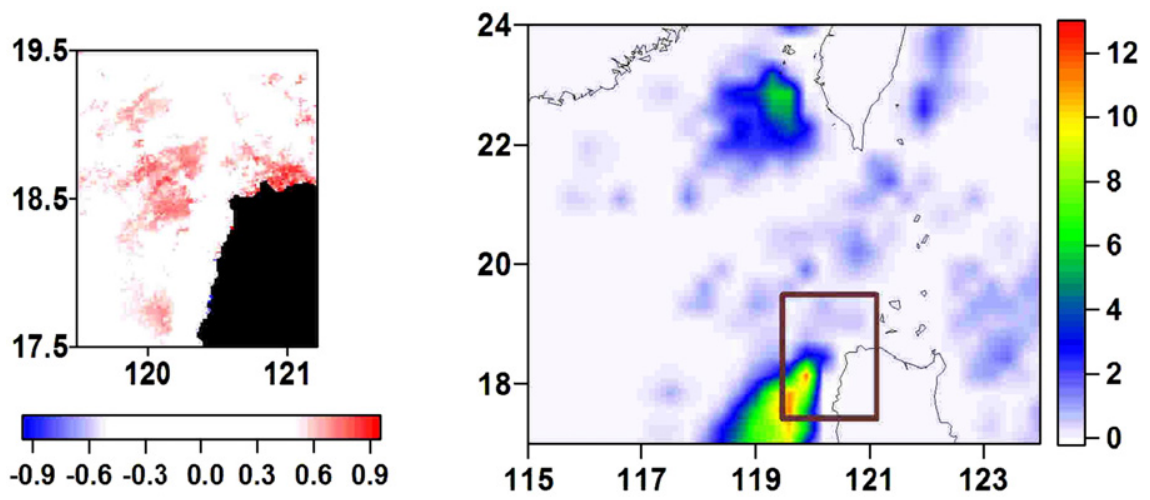

Fig. 7. Right image: wind stress curl frequency for curl values $>0.05 \times 10^{-5} \mathrm{~N} \mathrm{~m}^{-3}$ (December 2004). Left image: correlation coefficient $(r)$ between wind stress curl and chl- $a$ for 2004 where colored areas represent $|r| \geq 0.5$.

of bloom occurrence. Another positive wind stress curl (but slightly smaller and weaker) is simultaneously located southwest of Taiwan (Fig. 7).

Furthermore, results from the correlation analysis (Fig. 7) show a high correlation coefficient $(r>0.5)$ on the NWL. Influence of the wind stress curl, however, is only confined to a smaller area.

\subsection{The influence of river discharge}

Another factor that may influence the bloom formation in the area is the nutrients coming from the Cagayan River, which is the largest river in the Philippines. River discharge data show that the river reaches its peak discharge during November averaging to $706.6 \mathrm{~m}^{3} / \mathrm{s}(1969-1974)$. The discharge then starts to decrease in December. On the other hand, lowest discharge can be observed during April $\left(79.75 \mathrm{~m}^{3} / \mathrm{s}\right)$.

Analysis of the monthly image composites show that a high increase in TSS can be observed at the mouth of the river during November indicating the intensity of the river flow during the month. Results also present that the Cagayan River influence is only limited near the northern coast of Luzon (Fig. 8).

\section{Discussion}

The occurrence of phytoplankton bloom in Luzon Strait follows a monsoonal pattern. High chlorophyll concentration can be observed from November to March that extends to the northern SCS during its peak. Moreover, a lowering in SST can be observed when elevation in chl- $a$ occurs (Fig. 3). Further support was acquired from the pixel correlation result (Fig. 4) showing that the area with high chl- $a$ concentration gives the highest negative correlation coefficient with SST. This lowering of SST, concurrent with the increase in phytoplankton abundance during NE monsoon, could be interpreted as either the presence of considerable amount of cold water carrying new or regenerated nutrients coming from upwelling or just the seasonal change in surface heat flux due to atmospheric cooling that allows a more dynamic vertical mixing of nutrients. With regards to the latter factor, Shaw et al. (1996) argued that this possibility can be disregarded because of the absence of unusually low air temperature in the area that can initiate such cooling in the water and further suggested that the anomalously high heat loss in the area (approx. within the NWL area), which they calculated to about $300 \mathrm{~W} \mathrm{~m}^{-2}$, was due to upwelling. Udarbe-Walker and Villanoy (2001) suggested that the localized

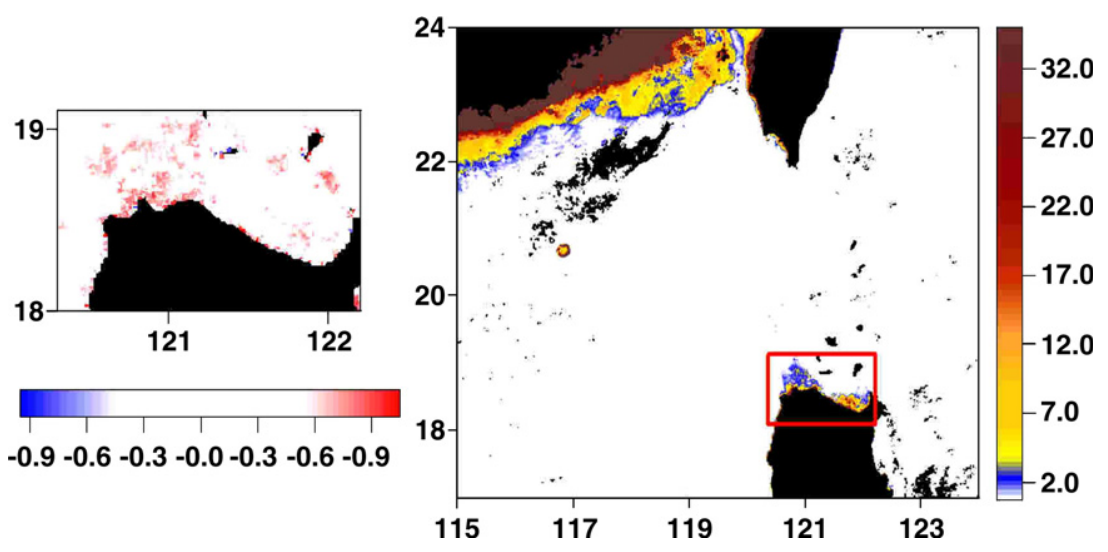

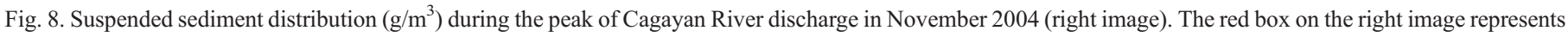

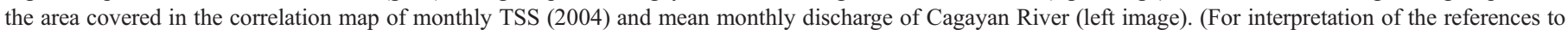
colour in this figure legend, the reader is referred to the web version of this article). 
cooling in this area is mainly due to advection of cold water by upwelling. Hence, we could not consider this possibility.

Another observation is that the occurrence of the bloom during NE monsoon is simultaneous to the presence of thermal fronts due to the intrusion of the Kuroshio (Fig. 5) and the northward movement of LCC, which has been previously documented to occur all year-round (Fang et al., 1998; Hu et al., 2000). Overlaying the traced fronts over a chl- $a$ image shows a rapid increase in chl- $a$ concentration along the western edge of the Kuroshio front. The sloping isopycnals along the western edge of the Kuroshio can induce upwelling by interaction with the topography and changes in position and acceleration. The high chlorophyll concentration that can be observed between the LCC front and the branch of Kuroshio entering the Babuyan Channel is most likely due to upwelling brought about by the opposing movements of the two currents and their interaction with the topography of the area. Fig. 6 shows that highest chl- $a$ concentrations are clustered near the western slope of the strait. This could suggest that the sills and ridges in the strait have influence in the upwelling. Further observations show that the variation in the position and intensity of monthly chlorophyll cluster is determined by the strength and position of Kuroshio intrusion. The high chlorophyll cluster moves southward and intensifies as Kuroshio penetrates strongly. Intrusion of Kuroshio during SW monsoon, however, is not evident in the satellite images due to the rapid increase of SST in the SCS during this season. It is also during this time that the wind advects SCS water against the Kuroshio. However, $\mathrm{Hu}$ et al. (2000) mentioned that intrusion can also happen in some other time of the year but of less intensity.

The remarkable increase in phytoplankton biomass during $\mathrm{NE}$ monsoon is also concurrent with the presence of two upwelling sites based on the results of wind stress curl analysis. These two upwelling sites, one located in the NWL region and another to the southwest of Taiwan, disappear during SW monsoon. Chao et al. (1996) have shown that a deep water upwelling also occurs to the southwest of Taiwan as a result of upward entrainment as Pacific water flows into the SCS through the Luzon Strait. On the other hand, upwelling in the NWL during NE monsoon has been identified in previous studies (Chao et al.,1996; Shaw et al., 1996; Udarbe-Walker and Villanoy, 2001). The effect of wind stress curl as a possible cause to the enhancement of the phytoplankton biomass was investigated by correlating the said parameter with the chl- $a$ concentration. Pixel correlation (Fig. 7), however, reveals the influence of wind stress curl to the seasonal abundance of phytoplankton albeit confined to a small area. The discrepancy between the location of wind stress curl and correlation result may be due to a north-west advection by the LCC.

Although upwelling has been pointed out by many as the main factor for the bloom, it is still necessary to investigate the possible effect of freshwater input to the area. In northern SCS, nutrient flux coming from the nearby rivers such as the Cagayan River and Pearl River may also contribute to the productivity of the area. Data show that Cagayan River peaks during November when phytoplankton bloom also occurs. The TSS near the mouth of Cagayan River intensifies during the peak of river discharge (Fig. 8). The influence of the river, however, is concentrated on its immediate vicinity showing consistently high in chl- $a$ concentration all throughout the year. Moreover, a high correlation to the west of Cagayan River mouth (Fig. 4), on the other hand, maybe due to the westward advection of currents. This area has also been shown to have a seasonal increase in chl- $a$ and a negative correlation between SST and chl- $a$. The deflection of a branch of Kuroshio penetrating into the Babuyan Channel near the mouth of Cagayan River (Fig. 5) likely traps the majority of the river discharge within few kilometers from the coast. Moreover, it is also during this season that the southward flow of Guangdong coastal current (GCC, Fang et al., 1998) carrying cold water from the East China Sea (ECS) occurs. It can be possible that ECS can contribute to the nutrient supply of the study area. In the study of Gong et al. (2003), it was found out that a high nutrient concentration was found south off the river mouth of Yangtze River, a river that flows to the ECS, and that it was due to the southward flow of GCC during NE monsoon.

Based upon the results, the intensity of the surface chlorophyll signal during NE monsoon as observed from the ocean color data is likely influenced more by the interaction of the current movement in the northern SCS than other factors. The strength of Kuroshio intrusion is seen to induce upwelling due to dynamic uplift by LCC as it encounters the Kuroshio. Baroclinic movements of these currents create a sea surface slope and pycnocline slope in opposite direction. In the study of Xue et al. (2004), the Ekman-induced movement of Kuroshio water during NE monsoon generates upwelling when moving upslope to the northern shelf of SCS. In addition to these current flows is the possible influence of the complicated bottom topography of the area. Wind and river have intermittent and spatially limited influence.

Furthermore, various factors that are not covered in this study may have contributed to seasonal biological abundance in this area. In their study, Niwa and Hibiya (2004) suggested the presence of intense turbulent mixing near the subsurface ridges in the strait based on a numerical model. Wang et al. (2003), on the other, observed the formation of the few cyclonic eddies during NE monsoon, in which the possible mechanisms for their formations are likely influenced by the Kuroshio intrusion to the northern SCS during NE monsoon. Thus, it is also interesting to consider these factors in the future studies.

\section{Conclusion}

This study shows that phytoplankton biomass in the Luzon Strait is greatly enhanced during NE monsoon, which is due to the intense upwelling. The upwelling is likely triggered by the interaction of the Kuroshio and the LCC during the NE monsoon. This upwelling could possibly be associated with the dynamic uplift by the LCC as it encounters the Kuroshio current. Bottom topography in the Luzon Strait could also play an important role on this phenomenon. Further studies on this matter, however, are highly needed. Furthermore, the positive wind stress curl plays an additional role in upwelling cold, nutrient-rich water. The 
contribution of Cagayan River, however, is limited within immediate vicinities.

\section{Acknowledgements}

The authors are grateful to Mr. Yannek Meunier of UPMarine Science Institute for his assistance in data processing, to the National Science Council of Taiwan for the financial support, and to the three anonymous reviewers for their invaluable help in improving the manuscript.

\section{References}

Centurioni, L. C., Niiler, P. P., \& Lee, D. -K. (2004). Observations of inflow of Philippine sea surface water into the South China Sea through the Luzon Strait. Journal of Physical Oceanography, 34(1), 113-121.

CERSAT - IFREMER (2002). QuikSCAT Scatterometer Mean Wind Field Products User Manual. Version 1.0, Ref. C2-MUT-W-03-IF, 47 pp. Available at http://www.ifremer.fr/cersat/en/documentation/manuals.htm

Chao, S. -Y., Shaw, P. -T., \& Wu, S. -Y. (1996). Deep water ventilation in the South China Sea. Deep-Sea Research, Part I, 43(4), 445-466.

Chen, Y. L., Chen, H. -Y., Karl, D. M., \& Takahashi, M. (2004). Nitrogen modulates phytoplankton in spring in the South China Sea. Continental Shelf Research, 24, 527-541.

Chen, Y. L., Chen, H. -Y., \& Lin, Y. -H. (2003). Distribution and downward flux of Trichodesmium in the South China Sea as influenced by the transport from the Kuroshio Current. Marine Ecology. Progress Series, 259, 47-57.

Chen, C. T. A., \& Huang, M. H. (1996). A mid-depth front separating the South China sea water and the Philippine sea water. Journal of Oceanography, 52, $17-25$.

Chen, C. T. A., Wang, S. L., Wang, B. J., \& Pai, S. C. (2001). Nutrient budgets for the South China Sea basin. Marine Chemistry, 75, 281-300.

Delu, P., Haiqing, H., Tingming, M., \& Zhehau, M. (1999). Ocean color remote sensing by SeaWIFS in China. Proceedings 1999 Asian Conference of Remote Sensing Available at http://www.gisdevelopment.net/aars/acrs/1999/ ts8/ts8348.asp

Fang, G., Fang, W., Fang, Y., \& Wang, K. (1998). A survey of studies on the South China Sea upper ocean circulation. Acta Oceanographica Taiwanica, 37(1), 1-16.

Farris, A., \& Wimbush, M. (1996). Wind-induced Kuroshio intrusion into the South China Sea. Journal of Oceanography, 52(6), 771-784.

Gomez, F., Gorsky, G., Garcia-Gorriz, E., \& Picheral, M. (2004). Control of the phytoplankton distribution in the Strait of Gibraltar by wind and fortnightly tides. Estuarine, Coastal and Shelf Science, 59, 485-497.

Gong, G. C., Liu, K. K., Liu, C. T., \& Pai, S. C. (1992). Chemical hydrography of the South China Sea and a comparison with the West Philippine Sea. Terrestrial, Atmosphere, and Ocean Sciences, 3, 587-602.

Gong, G. C., Wen, Y. H., Wang, B. W., \& Liu, G. J. (2003). Seasonal variation of chlorophyll $a$ concentration, primary production and environmental conditions in the subtropical East China Sea. Deep-Sea Research, Part II, 50, 1219-1236.

Ho, C. -R., Zheng, Q., .Kuo, N. -J., Tsai, C. -H., \& Huang, N. E. (2004). Observation of the Kuroshio intrusion region in the South China Sea from AVHRR data. International Journal of Remote Sensing, 25(21), 4583-4591.

Hu, J., Kawamura, H., Hong, H., \& Qi, Y. (2000). A review on the currents in the South China Sea: Seasonal circulation, South China Sea warm current and a southwestward current and Kuroshio intrusion. Journal of Oceanography, 56, 607-624.

Large, W. G., \& Pond, S. (1981). Open ocean momentum flux measurements in moderate to strong winds. Journal of Physical Oceanography, 11, 324-336.

Liu, K. -K., Chao, S. -Y., Shaw, P. -T., Gong, G. C., Chen, C. C., \& Tang, T. Y. (2002). Monsoon-forced chlorophyll distribution and primary production in the South China Sea: Observations and a numerical study. Deep-Sea Research, Part I, 49, 1387-1412.

Liu, W. T., \& Tang, W. (1996). Equivalent neutral wind.JPL Publication, vol. 96-17. Available at http://airsea-www.jpl.nasa.gov/data/data.html

Metzger, E. J., \& Hurlburt, H. E. (2001). The nondeterministic nature of the Kuroshio penetration and the eddy shedding in the South China Sea. Journal of Physical Oceanography, 31, 1712-1732.

Metzger, E. J., \& Hurlburt, H. E. (2001). The importance of high horizontal resolution and accurate coastline geometry in modeling South China Sea inflow. Geophysical Research Letters, 28(6), 1059-1062.

Nitani, H. (1972). Beginning of the Kuroshio. In H. Stommel \& K. Yoshida (Eds.), Kuroshio: Physical aspects of the Japan Current (pp. 129-164). Seattle: University of Washington Press.

Niwa, Y., \& Hibiya, T. (2004). Parameterization of turbulent diffusivity in the deep ocean. Annual Report of the Earth Simulator Center, Chapter 1: Atmospheric and Oceanic Simulation (pp. 53-56). Available at http://www. es.jamstec.go.jp/esc/images/annualreport2003/

Pinazo, C., Millet, B., Marsaleix, P., Estournel, C., Kondrachoff, V., \& Vehil, R. (2001). Phytoplankton variability in summer in the northwestern Mediterranean: Modelling of the wind and freshwater impacts. Journal of Coastal Research, 17(1), 146-161.

$\mathrm{Qu}$, T. (2000). Upper-layer circulation in the South China Sea. Journal of Physical Oceanography, 30, 1450-1460.

Sangra, P., Basterretxea, G., Pelegri, J. L., \& Aristegui, J. (2001). Chlorophyll increase due to internal waves on the shelf break of Gran Canaria (Canary Islands). Sciantia Marina, 65(Suppl. 1), 89-97.

Shaw, P., \& Chao, S. (1994). Surface circulation in the South China Sea. DeepSea Research, Part I, 41, 1663-1683.

Shaw, P. -T., Chao, S-Y., Liu, K. -K., Pai, S. -C., \& Liu, C. -T. (1996). Winter upwelling off Luzon in the northeastern South China Sea. Journal of Geophysical Research, 101(C7), 16435-16448.

Signorini, S. R., McClain, C. R., \& Dandonneau, Y. (1999). Mixing and phytoplankton bloom in the wake of Marquesas Islands. Geophysical Research Letters, 26(20), 3121-3124.

Tang, D. L., Ni, I. H., Kester, D. R., \& Müller-Karger, F. E. (1999). Remote sensing observations of winter phytoplankton blooms southwest of the Luzon Strait in the South China Sea. Marine Ecology. Progress Series, 191, 43-51.

Tomczak, M. (1998). Island wakes in deep and shallow water.Shelf and Coastal Oceanography, Chapter 7. Available at http://www.es.flinders.edu.au/ mattom/ShelfCoast/index.html

Toole, J. M., Millard, R. C., Wang, Z., \& Pu, S. (1990). Observation of the Pacific North Equatorial Current bifurcation at the Philippine coast. Journal of Physical Oceanography, 20, 307-318.

Udarbe-Walker, M. J. B., \& Villanoy, C. L. (2001). Structure of potential upwelling areas in the Philippines. Deep-Sea Research, Part I, 48, $1499-1518$.

Wang, G. H., Su, J. -L., \& Chu, P. C. (2003). Mesoscale eddies in the South China Sea observed with altimeter data. Geophysical Research Letters, 30 (21). doi:10.1029/2003GL018532

Xue, H., Chai, F., Pettigrew, N., Xu, D., Shi, M., \& Xu, J. (2004). Kuroshio intrusion and the circulation in the South China Sea. Journal of Geophysical Research, 109, C02017. doi:10.1029/2002JC001724 